\title{
El golpe de estado de Primo de Rivera a través de la prensa nacional. Un análisis comparativo
}

\author{
The coup d'etat of Primo de Rivera through the national press. A \\ comparative analysis
}

\author{
DAVID MORALES DÍAZ \\ Universidad Nacional de Educación a Distancia \\ davmorales@talavera.uned.es
}

Resumen: El presente trabajo analiza las opiniones y posiciones que la prensa nacional manifestó ante el golpe de Estado de Primo de Rivera en 1923. Se estudian las diferentes líneas editoriales de las publicaciones periódicas de la capital de España y una selección de las mismas de la geografía nacional, estableciendo un análisis comparativo que defina una visión general de la opinión pública ante este hecho tan singular para la historia del país.

Palabras clave: Miguel Primo de Rivera, historia de la prensa española, golpe de Estado, dictadura española, análisis editorial.

Abstract: The present work analyzes the opinions and positions that the national press manifested about of the coup d'etat of Primo de Rivera in 1923. We study the different editorial lines of regular publications of the capital of Spain and a selection of the same ones of the national geography, establishing a comparative analysis that defines an overview of the public opinion about this fact so singular for the history of the country.

Keywords: Miguel Primo de Rivera, history of the Spanish press, coup d'etat, Spanish dictatorship, editorial analysis.

Recibido: 22 de febrero de 2017; aceptado: 19 de junio de 2017; publicado: 27 de marzo de 2018. Revista Historia Autónoma, 12 (2018), pp. 171-190.

e-ISSN: 2254-8726; DOI: https://doi.org/10.15366/rha2018.12.009. 
Introducción

El golpe de Estado del General Primo de Rivera del 13 de septiembre de 1923 acabó con el régimen constitucional vigente en España, dominado por los partidos liberales y un sistema turnista anquilosado. La conflictividad social, el caciquismo, la Guerra de Marruecos, los nacionalismos periféricos, la pérdida de la influencia internacional y el mal desarrollo de la economía después de la Gran Guerra habían sumido la vida del país en un estado de inoperancia y confusión política.

Las fuentes hemerográficas de este periodo han sido normalmente tratadas como complemento de estudio y no como fuentes principales, lo que constituye motivo suficiente para emprender este trabajo. Nuestro análisis se centra en las impresiones manifestadas a través de los editoriales y artículos de la prensa nacional acerca del golpe de Estado, analizados según tendencias ideológicas. Para ello, nos hemos situado cronológicamente en el mismo día 13 de septiembre de 1923, momento en que tuvo lugar la sublevación, lo que permite analizar las opiniones más inmediatas.

Durante la primera mitad del siglo $\mathrm{xx}$, la prensa española fue el gran medio de comunicación de masas. Amparada bajo la Ley de Prensa de 1883, aumentó en cabeceras hasta la implantación de la Dictadura de Primo de Rivera. La publicación política, frente a la tradicional de información del siglo XIX, cobró cada vez más importancia y representó las distintas tendencias ideológicas dentro del país. Algunas de las grandes cabeceras procedían del siglo anterior: La Vanguardia, El Imparcial... pero el aumento de pequeñas y grandes empresas editoriales, algunas derivadas de diarios anteriores como El Liberal y La Libertad, presentaron un nuevo modelo de negocio. La mayoría fueron empresas pequeñas, aunque dominaban los grandes industriales, capaces de organizarse en "trusts" empresariales, donde la búsqueda de financiación y la compra-venta de diarios se hicieron palpables; nombres como El Sol, de Nicolás María de Urgioti, representan un buen ejemplo de este modelo de negocio que llegaba incluso a controlar la producción de pape ${ }^{1}$. Así, los grandes centros periodísticos, donde más ejemplares se vendían, fueron las ciudades de Madrid y Barcelona, por lo que sirvieron de modelo y tendencia para el resto de la prensa nacional.

Sobre la Dictadura de Primo de Rivera se han realizado estudios generales que han descrito sus causas, desarrollo y consecuencias. No obstante, apenas hay trabajos que realicen una visión de este hecho a través de la prensa. La historiografía de este período se ha extendido desde los mismos coetáneos de la dictadura hasta la actualidad, tal y como nos muestra Julio López Íñiguez en Noventa años de historiografía sobre la Dictadura de Primo de Rivera: un

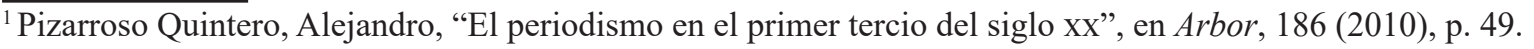


estado de la cuestión ${ }^{2}$. Pero, para los análisis sobre la prensa de la época, hay que destacar el trabajo realizado por María Dolores Saiz García y María Cruz Seoane, Historia del periodismo en España. El siglo XX (1898-1936)³, que muestra una amplia síntesis sobre la situación de la misma en el ámbito social y político. No obstante, aunque hemos realizado una tarea de búsqueda de trabajos que analicen las reacciones de la prensa ante el golpe de Estado, todas las investigaciones confluyen en la situación por la que pasó la misma durante el régimen dictatorial: los diarios vigentes, la censura, las comunicaciones, etc. Otros artículos se acercan a nuestra propuesta aunque de forma escueta, tal es el caso de La Dictadura de Primo de Rivera: entre el control y la censura (1924-1930), de Lorena Romero Rodríguez ${ }^{4}$, que expone un pequeño comentario sobre la actitud de varios diarios de tirada nacional ante el golpe de Estado; o la descripción que realiza María José Ruiz Acosta sobre la utilización de la prensa y la censura como fuente de investigación en Dictadura, censura y prensa en España: 1923-19305.

Desde otro punto de vista, el análisis de la actuación de la prensa extranjera permite expresar que fue crítica al régimen dictatorial, de acuerdo a La prensa como fuente: «España con honra», un semanario contra la dictadura de Primo de Rivera de Valentín del Arco López 6 . En este libro se analizan textos de una serie de autores en el exilo de la talla de Miguel de Unamuno o Blasco Ibáñez. Del mismo modo, y más próxima a la propuesta de nuestro trabajo, destacamos La Oposición a la Dictadura de Primo de Rivera a través de la prensa mercurial chilena (1923-1930), de Mario Valdés Urrutia, texto que detalla las reacciones de este diario chileno respecto del golpe de Estado ${ }^{7}$.

Para nuestro análisis ha sido necesario realizar una contextualización histórica a través de la consulta de bibliografía especializada. Así, las obras Historia Política. 1875-19398 y La España de Primo de Rivera: la modernización autoritaria ${ }^{9}$ nos revelan la Dictadura en todas sus vertientes. El acceso a las fuentes utilizadas viene dado por el desarrollo de multitud de proyectos de digitalización, que nos permiten una mejor disposición de los documentos históricos que conservan las administraciones públicas, universidades, fundaciones, centros privados, etc., y que facilitan su consulta a través de la red. Por ello, para la realización de este

\footnotetext{
${ }^{2}$ Íñiguez López, Julio, "Noventa años de historiografía sobre la Dictadura de Primo de Rivera: un estado de la cuestión", en Historiografías, 10 (2015), pp. 85-108.

${ }^{3}$ Saiz García, María Dolores y María Cruz Seoane, Historia del periodismo en España. El siglo XX: 1898-1936, Madrid, Alianza Editorial, 1998.

${ }^{4}$ Romero Rodríguez, Lorena, "La Dictadura de Primo de Rivera: entre el control y la censura (1924-1930)", en Laga Nuño, Concha (dir.), Un siglo de Información en Sevilla (Prensa, Radio y Televisión) 1909-2009, Sevilla, Universidad de Sevilla, 2009, pp. 51-82.

${ }^{5}$ Ruiz Acosta, María José, “Dictadura, censura y prensa en España: 1923-1930”, en Parias Sáinz de Rozas, María et al. (coords.), Comunicación, historia y sociedad: homenaje a Alfonso Braojos, Sevilla, Universidad de Sevilla, 2001, pp. 577-586.

${ }^{6}$ Del Arco López, Valentín, "La prensa como fuente: «España con honra», un semanario contra la dictadura de Primo de Rivera”, en Studia Historica. Historia Contemporánea, 6-7, (1988), pp. 113-142.

${ }^{7}$ Valdés Urrutia, Mario, "La oposición a la Dictadura de Primo de Rivera a través de la prensa mercurial chilena (1923-1930)", en Historia Actual Online, 25 (2011), pp. 125-143.

${ }^{8}$ Avilés Farré, Juan (coord.), Historia Política, 1875-1939, Madrid, Itsmo, 2001.

${ }^{9}$ González Calleja, Eduardo, La España de Primo de Rivera: la modernización autoritaria, Madrid, Alianza Editorial, 2006.
} 
trabajo, hemos efectuado una búsqueda lo más amplia posible de la prensa disponible para el año 1923, consultando y analizando un total de cuarenta y siete publicaciones. Hemos accedido a través de la Hemeroteca Digital de la Biblioteca Nacional de España, la Biblioteca Virtual de Prensa Histórica, la Hemeroteca de la Fundación Pablo Iglesias, GALICANA ${ }^{10}$, Biblioteca de Cataluña, LIBURUKLIK ${ }^{11}$ y la consulta de varios diarios que han puesto a disposición su hemeroteca digital en red.

Los editoriales y artículos de las publicaciones periódicas reflejan la opinión pública del país, por lo que los analizaremos ante un hecho de tal importancia como un golpe de Estado. Nuestro planteamiento responde a varias cuestiones: estudiar la posición de la prensa en general, comparando entre los diferentes tipos de periódicos la ideología reflejada y la manifestación de la sociedad respecto del acontecimiento en los mismos; describir qué grupos estuvieron a favor y cuáles en contra, qué justificaciones dieron para ello y qué se esperaba por parte de estos órganos de expresión ante este acontecimiento.

Para realizar dicha comparación, hemos dividido el texto por tendencias ideológicas. Primeramente, expondremos una breve contextualización histórica donde presentamos la coyuntura social y política del país en el momento justo en que se produjo el levantamiento. El cuerpo central del análisis comienza con el estudio de los periódicos liberales de diferentes tendencias, que son los de mayor número y tirada. Seguidamente, mostraremos la posición de las publicaciones periódicas de la prensa obrera y sindicalista. Luego, abordaremos los medios republicanos y nacionalistas, y terminaremos con los tradicionalistas y católicos. Como último apartado, expondremos las conclusiones a la que hemos llegado tratando de responder a las cuestiones propuestas.

La metodología y las técnicas utilizadas han versado sobre la recopilación de publicaciones periódicas disponibles. Hemos seleccionado una serie de diarios que tenían una elevada difusión en grandes ciudades como Madrid o Barcelona, pero también hemos realizado una elección de otras cabeceras que cubren o representan geográficamente la prensa del país en esa época. Una buena parte de ellas contienen series completas que han permitido examinar los números anteriores y posteriores al golpe de Estado. De otras, en cambio, solo disponemos de números no correlativos. En conjunto, hemos realizado una labor de lectura de cada uno de aquellos que hemos considerado relevantes para esta investigación; en ese sentido, hemos elaborado una lista de referencias que nos ha permitido obtener una serie de puntos en común y así poder realizar y plasmar un estudio comparativo.

\footnotetext{
${ }^{10}$ Biblioteca Digital de Galicia.

${ }^{11}$ Biblioteca Digital Vasca.
} 
1. La prensa nacional y el golpe de Estado

La situación de España durante los días anteriores al golpe de Estado de septiembre de 1923 presenta una serie de características que explican las causas generales por las que Miguel Primo de Rivera se sublevó contra el orden constitucional establecido. Desde 1917, la situación económica del país se había agravado considerablemente, lo que aumentó la conflictividad social y evidenció rasgos de una futura revolución social. La formación de las Juntas de Defensa Militares como medida de presión ante el débil gobierno central también presentaba conatos de insurrección. La guerra en Marruecos fue criticada desde la península por su alto coste en vidas y recursos, siendo el Desastre del Annual de 1921, lugar donde el ejército español recibió una amplia derrota frente a las cabilas rifeñas, lo que acentuó dicha crisis. Además, la organización de una asamblea de parlamentarios extraoficial, que intentó abrir un proceso constituyente al margen de los partidos del turno con el nacionalismo conservador catalán a la cabeza, demandó más participación en la política del país. Las reivindicaciones autonomistas y nacionalistas arreciaban y, por último, el caciquismo y la corrupción fueron percibidos como un mal endémico de difícil erradicación.

En consecuencia, se sucedían los gobiernos ante la presión de los acontecimientos. Tal fue el fracaso de Maura, Sánchez de Toca o Manuel Allendesalazar sucesivamente. El aumento de las huelgas y la represión gubernativa tensaron aún más la situación. Las críticas al sistema liberal llegaron incluso desde el propio rey Alfonso XIII, que acentuó la necesidad de un cambio de régimen. Maura lo volvió a intentar con un gobierno de concentración y para cuando el marqués de Alhucemas, Manuel García Prieto, llegó a la presidencia en diciembre de 1922, el golpe de Estado ya se estaba fraguando. Así, Primo de Rivera, que había sido designado Capitán General de Barcelona ese mismo año y se había ganado a las clases conservadoras por su celo antiterrorista, el 13 de septiembre de 1923, declaró el estado de guerra y exigió al Rey la dimisión del Gobierno y la concesión de poderes. García Prieto presentó la dimisión y Alfonso XIII dio su apoyo al nuevo proyecto.

\subsection{La prensa liberal}

El liberalismo abarcaba un espectro ideológico que presentaba muchos puntos coincidentes y otros distantes, siendo su prensa la que mayor número de publicaciones tenía por entonces. Presentamos aquí una serie de aspectos concretos que encontramos en sus editoriales. 


\subsubsection{Justificaciones del golpe de Estado}

Para este sector, las causas que justifican el golpe de Estado aluden como acusación directa a los partidos liberales. El Heraldo de Madrid atribuyó a estos partidos todos los problemas de forma general, tales como la conflictividad social, las huelgas o la guerra de Marruecos ${ }^{12}$. El Sol, aunque se compadecía del liberalismo, anunció la insurrección como el fin del crédito dado al mismo por parte del pueblo y del rey ${ }^{13}$. Del mismo modo, el diario La Opinión, hizo un claro ataque a los gobernantes por su ineptitud, y advirtió que el ejército venía proyectando señales de revolución inequívocas ${ }^{14}$.

En otros puntos del país se repiten dichos argumentos. Crónica Meridional de Almería presentó el levantamiento como parte del descontento de la sociedad ${ }^{15}$. Su vecino más conservador, Diario de Almería, esgrimió como motivo principal el agravio realizado por los separatistas y definió la corrupción como un mal a extirpar ${ }^{16}$. En Valencia, La Correspondencia de Valencia denunciaba el adormecimiento social que había respecto de los problemas del país y calificó de normal la actitud del Ejército ${ }^{17}$. El diario murciano El Tiempo, más conservador, expuso la llegada del movimiento militar como un cúmulo de despropósitos por parte del gobierno. Así, la destitución de Martínez Anido, gobernador de Barcelona, gran represor de las organizaciones obreras meses antes, fue tomada como una de las causas principales del golpe de Estado. Sus referencias al nacionalismo pasaban por denominaciones como "virus y epidemia"18. La Voz de Asturias avisó sobre la llegada de un movimiento revolucionario anárquico o militar ante la mala actuación del gobierno central ${ }^{19}$. El diario numantino El Porvenir Castellano atribuyó los males del país a la inactividad de los gobiernos liberales frente al separatismo ${ }^{20}$, tal y como lo hizo desde Amposta El Eco de la Comarca, que los acusaba de la situación en la que se encontraba la región catalana ${ }^{21}$.

\subsubsection{La ilegitimidad del golpe de Estado}

Desde las páginas de El Imparcial se tildó de ilegal el movimiento militar, si bien señalaban que los fines propuestos eran los correctos; lamentaron que hubiera tenido que ser el Ejército el

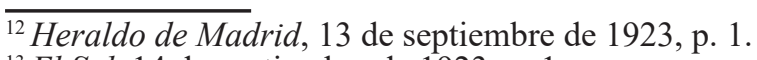

${ }^{13}$ El Sol, 14 de septiembre de 1923, p. 1.

${ }^{14}$ La Opinión, 13 de septiembre de 1923, p. 1.

${ }^{15}$ Crónica Meridional, 14 de septiembre de 1923, p. 1.

16 “Ante el nuevo régimen", en Diario de Almería, 20 de septiembre de 1923, p. 1.

17 "Nuestra posición", en La Correspondencia de Valencia, 13 de septiembre de 1923, p. 1.

18 “Temas políticos", en El Tiempo, 12 de septiembre de 1921, p. 1; "El error catalanista", en El Tiempo, 13 de septiembre de 1921, p. 1.

19 "Recordando la labor de los Concentrados", en La Voz de Asturias, 18 de septiembre de 1923, p. 1.

20 "El nuevo régimen" en El Porvenir Castellano, 17 de septiembre de 1923, p. 1; "Por el buen camino", en El Porvenir Castellano, 20 de septiembre de 1923, p. 1.

21 "Cambio de régimen", en El Eco de la comarca, 16 de septiembre de 1923. p. 1.
} 
que iniciara el cambio ${ }^{22}$. En la misma línea se situó El Sol, que presentó al movimiento castrense como heredero de las Juntas de Defensa y legitimó el golpe por la inactividad de la sociedad ${ }^{23}$.

El Ministro de Gobernación Santiago Alba tuvo en el diario La Libertad su órgano de expresión y desde ahí atacó al movimiento militar acusándolo de "impunista", es decir, señalando que la sublevación era una maniobra militar que buscaba salvar a aquellos que estaban siendo investigados por el Desastre del Annual24. Del mismo modo, se apoyó al gobierno de concentración desde El Heraldo de Zamora, que manifestó que no harían una defensa de la rebelión, ya que el proceso de regeneración debía realizarse por medios constitucionales y con respeto a la monarquía ${ }^{25}$. El Orzán coruñés censuró el golpe por su ilegalidad y lo comparó con los pronunciamientos militares del siglo $\mathrm{XIX}^{26}$. Desde otro punto de vista, el Heraldo de Madrid modificó su opinión y expresó que la sublevación sería legal, si se evidenciaba que la finalidad de la misma consistía en el desarrollo de un nuevo Estado constitucional27.

\subsubsection{Análisis de la situación, expectativas y consecuencias}

La sublevación en sí, lo que se esperaba de ella y el modo de actuación de los militares ocuparon bastantes líneas. El Heraldo de Madrid expresó que la mejor manera de solucionar los problemas del país no era a través de un levantamiento militar, y por ello rechazó la posibilidad de un proceso dictatorial, del cual suponían que tendría un carácter arbitrario en sus actuaciones. En esa línea, clamaron por el mantenimiento del régimen democrático. La regeneración, pensaban, pasaría por unas nuevas Cortes, pero su malestar ante la complacencia del rey representó un aviso sobre las consecuencias que tendría en un futuro. Pidieron la vuelta a la legalidad democrática y demandaron al Ejército que se apoyara en una base social2 ${ }^{28}$.

La confianza en Alfonso XIII también fue analizada por El Imparcial, que presentó su figura como la solución capaz de dar una salida constitucional a la situación. Recomendaron a los golpistas que se apoyasen en la base popular y advirtieron sobre los posibles problemas de un Directorio Militar ${ }^{29}$. El aristocrático La Época mostró su preocupación por la inoperancia del gobierno saliente y calificó el acontecimiento como "funesto descarrilamiento" ${ }^{30}$. $A B C$ describió la serenidad con que el país había recibido el levantamiento y mostró alegría por la caída del régimen pero no así por la suerte del último gobierno. El advenimiento de una dictadura les pareció una solución eficaz, pero coincidió con otros en que era necesario que se desarrollase con el apoyo de las clases populares; de lo contrario, la revolución asaltaría al poder. Señaló

\footnotetext{
$\overline{{ }^{22} \text { El Imparcial, } 14}$ de septiembre de 1923, p.1.

${ }^{23}$ El Sol, 14 de septiembre de 1923, p.1.

24 "Impunismo desesperado", en La Libertad, 13 de septiembre de 1923, p.1.

${ }^{25}$ Heraldo de Zamora, 14 de septiembre de 1923, p. 1.

${ }^{26}$ El Orzán, 14 de septiembre de 1923, p. 1.

${ }^{27}$ Heraldo de Madrid, 14 de septiembre de 1923, p. 1.

${ }^{28}$ Heraldo de Madrid, 14 de septiembre de 1923, p. 1; y 15 de septiembre de 1923, p. 1.

${ }^{29}$ El Imparcial, 14 de septiembre de 1923, p. 1; 15 de septiembre de 1923, p. 1; y 16 de septiembre de 1923 , p. 1.

${ }^{30}$ La Época, 13 de septiembre de 1923, p. 1; 14 de septiembre de 1923, p. 1; y 15 de septiembre de 1923, p. 1.
} 
como grave el establecimiento de un Directorio Militar, pero se comprometió a prestar apoyo a los militares ${ }^{31}$.

El Sol se mantuvo a la expectativa de la evolución de los acontecimientos y presentó el golpe como la continuación del establecimiento de las Juntas de Defensa, acusando a los golpistas de imparcialidad en la publicación de los nuevos decretos. Aprobó la caída del anterior régimen pero, de igual modo que El Imparcial, mantuvo que todo cambio político debía hacerse con el apoyo social para no caer en los mismos errores que los liberales ${ }^{32}$. Dramáticamente, $L a$ Libertad presentó la situación como un golpe directo al poder civil, a la democracia y la libertad. Manifestó su desconfianza ante el contenido del Manifiesto de Primo de Rivera y anunció un futuro lleno de conflictividad. Un nuevo gobierno suponía para ellos la llegada del caos, la huelga general y la paralización del país. La consideración de "impunista" apareció en todos sus editoriales y clamó por que la solución pasara por el procesamiento de los responsables del Desastre del Annual. Su postura evolucionó una vez establecida la censura, para terminar apoyando el golpe de Estado como modelo de regeneración democrática y constitucional ${ }^{33}$. Dicha regeneración también es demandada desde La Correspondencia de España, que recalcó que el gobierno militar debía ser provisional y rechazó la opción de la dictadura ${ }^{34}$. Para $L a$ Opinión, los acontecimientos fueron antidemocráticos pero no restaron ninguna legitimidad, dada la situación en que se encontraba el país, de la que responsabilizó a los partidos liberales por no haber sabido responder debido a su inoperancia. La Dictadura era vista como un evento regresivo, y por ello demandaron que los cambios se hicieran constitucionalmente y con el apoyo de la base social. Por el contrario, los nuevos decretos del Directorio fueron alabados por este diario, que demandó una mayor profundización en las medidas de regeneración ${ }^{35}$.

En Barcelona, La Vanguardia presentó como causa directa de los acontecimientos los agravios realizados por los separatistas y definió a Barcelona como un hervidero de movimientos revolucionarios. Justificó el golpe dada la situación de "amodorramiento" del país; en su opinión, Madrid era una ciudad de acomodo de la corrupción política. También hizo una comparación con los pronunciamientos militares del siglo XIX, y resaltó la rapidez y la eficacia como base de su éxito. Según ellos, el pacifismo del movimiento se explica por el estado de conciencia colectiva que lo daba por hecho. Alabó a Primo de Rivera por utilizar Barcelona como punto de partida y describió la caída de los políticos liberales con un ejemplo del desánimo que reinaba en la política española. Por último, defendió el constitucionalismo como legitimación

\footnotetext{
${ }^{31} A B C, 14$ de septiembre de 1923 , p. 10; y 15 de septiembre de 1923, p. 7.

${ }^{32}$ El Sol, 14 de septiembre de 1923, p. 1; y 18 de septiembre de 1923, p. 1.

33 "Ante la razón de la fuerza", en La Libertad, 14 de septiembre de 1923, p. 1; y "Ahora más que nunca", en $L a$ Libertad, 15 de septiembre de 1923, p. 1.

${ }^{34}$ La Correspondencia de España, 13 de septiembre de 1923, p. 1.

${ }^{35}$ La Opinión, 13 de septiembre de 1923, p. 1; 14 de septiembre de 1923, p. 1; y 20 de septiembre de 1923 , p. 1.
} 
del golpe porque, para ellos, las Cortes estaban secuestradas por el profesionalismo político de los partidos liberales ${ }^{36}$.

Desde otros puntos del país, el almeriense Crónica Meridional manifestó la esperanza de regeneración democrática y la purga del liberalismo. La "extirpación” del caciquismo hizo que este diario reclamara la aparición de un nuevo Mussolini para España ${ }^{37}$. El Diario de Almería presentó el movimiento militar como una evolución y no como una revolución, manifestando que lo importante era la desaparición del caciquismo y no la denominación que reciba el levantamiento ${ }^{38}$. También, desde Andalucía, el Noticiero Gaditano aplaudió la actuación del Rey al posicionarse con los golpistas y la posible solución al problema de $\operatorname{Marruecos}^{39} ; E l$ Telegrama del Rif, muy cerca del conflicto bélico, calificó el movimiento como "renovador" y "salvador de la patria" y presentó la demanda de la figura del "cirujano de hierro" de Joaquín Costa: metafóricamente se presentaba a España como un país enfermo necesitado de una cura a través de una purga, materializada esta en los decretos publicados por el Directorio Militar ${ }^{40}$.

La Correspondencia de Valencia apoyó a los políticos liberales, pero su evolución fue rápida a favor de los militares, manifestando que la publicación de los nuevos decretos y el sentido de regeneración del manifiesto iban por el buen camino. Aunque no compartía la ideología de los golpistas, expresó que el cambio era necesario y presentó el golpe como un acto diferente a los pronunciamientos del siglo XIX. Para este diario, Primo de Rivera era la persona que debía buscar el consenso apoyándose en las clases medias, en consonancia con el fascismo italiano. De igual modo, publicaron parte de los escritos de Joaquín Costa en torno al proceso regenerador del país. ${ }^{41}$

Las Provincias de Valencia fue más escueto y describió el golpe de Estado como un proceso regenerador, presentando a Primo de Rivera como un redentor. Esperaban que los nuevos decretos acabaran con la obra que había realizado "un Parlamento elegido desde arriba"42. El diario conservador murciano El Tiempo describió el movimiento más como una reacción ante los políticos liberales que como una acción contra ellos. Opinaban que si no hubieran sido los militares los primeros en dar el paso, se habría hecho por vía del anarquismo y el comunismo, lo que habría empeorado aún más la situación del país ${ }^{43}$.

\footnotetext{
36 "La bicefalia española", en La Vanguardia, 19 de septiembre de 1923, p. 11; "La acogida de un nuevo régimen", en La Vanguardia, 15 de septiembre 1923, p. 11; La Vanguardia, 14 de septiembre, p. 3; 18 de septiembre, p. 6; y 21 de septiembre de 1923, p. 10.

37 “La Solución”, en Crónica Meridional, 16 de septiembre de 1923, p. 1; e "Ilusiones y esperanzas", en Crónica Meridional, 17 de septiembre de 1923, p. 1.

38 “Ante el nuevo régimen", en Diario de Almería, 20 de septiembre de 1923, p. 1.

39 “Ante la revolución triunfante y vitoreada", en Noticiero Gaditano, 15 de septiembre de 1923, p. 1.

${ }^{40}$ El Telegrama del Rif, 18 de septiembre de 1923, p. 1; y 20 de septiembre de 1923, p. 1.

41 "Nuestra posición", "Las tres hermanas" y "La voz de Costa", en La Correspondencia de Valencia. 13, 15 y 17 de septiembre de 1923, p. 1.

${ }^{42}$ Las Provincias, 15 de septiembre de 1923, p. 1; y 16 de septiembre de 1923, p. 1.

43 "Estamos sobre un volcán", en El Tiempo, 14 de septiembre de 1923, p. 1; y El Tiempo, 20 de septiembre de 1923 , p. 1.
} 
En Castilla, El Porvenir Castellano de Soria confió en el movimiento como un proceso regenerador y se alegró por el decreto de restructuración del funcionariado ${ }^{44}$. Nueva Iberia, de Ciudad Rodrigo, también se unió a la definición de movimiento regenerador contra el caciquismo imperante ${ }^{45}$. Por su parte, $\mathrm{La}$ Voz de Soria describió el movimiento como el comienzo de una nueva era contra la desidia con que se trataban los asuntos del país. También utilizaron a Joaquín Costa para denominar a Primo de Rivera como "cirujano" y describieron que cualquier movimiento, militar o no, habría tenido igualmente el beneplácito de la sociedad. Reflexionaron sobre un posible fracaso del golpe y manifestaron cierto temor por igual ante una Dictadura, como a un gobierno socialista ${ }^{46}$. La posición que tomó Alfonso XIII fue alabada por El Diario Palentino, que consideró un acierto poner a tecnócratas al frente de los ministerios y la eliminación de los gobiernos civiles ${ }^{47}$. Desde el punto de vista contrario, el golpe de Estado se definió como el peor momento de crisis de la actualidad política por La Provincia de Teruel y reiteró que se debía contar con el apoyo social para realizar el cambio ${ }^{48}$.

En Galicia, se felicitaron por la limpieza y la tranquilidad con que se llevó a cabo el movimiento militar desde El Progreso de Lugo, ante el hartazgo anterior ${ }^{49}$. El Orzán coruñés también se hizo eco de dicha calma, ya fuese esta por desconocimiento de la gravedad del hecho o por indiferencia, representando ese concepto de desidia popular que planea por todas las opiniones de la prensa nacional. Lo calificaron de "pronunciamiento" y describieron la situación del gobierno de concentración como débil. Tildaron de inconcreto el manifiesto de Primo de Rivera, pero esperaron que fuera la mejor solución, puesto que contaba con el apoyo del rey ${ }^{50}$. Por último, desde Santiago de Compostela, El Eco de Santiago también alabó la serenidad con que la sociedad había acogido el movimiento militar, aunque eran simpatizantes del sistema parlamentario y constitucional. Para ellos, los culpables del estado anterior son los que debían responder, acusando directamente al Ministro de Gobernación, Santiago Alba ${ }^{51}$.

Por su parte, La Voz de Asturias presentó un análisis bastante extenso del movimiento, y realizó un ataque directo al caciquismo y al Ministro de Gobernación. Para este medio, el golpe debía ser regenerador. Tras la publicación del manifiesto de Primo de Rivera, expresó sus dudas ante la efectividad de las reformas, las cuales debían ser transitorias y sin caer en autoritarismos. Este diario es de los pocos que se preguntó por el silencio de los partidos liberales y por la actitud de espera de la izquierda. Le extrañó que nadie defendiera el constitucionalismo y analizó las causas de la pérdida de apoyo de los partidos conservadores liberales. Su conclusión: el

\footnotetext{
44 “El nuevo régimen”, en El Porvenir Castellano, 17 de septiembre de 1923, p. 1; y "Por el buen camino", en El Porvenir Castellano, 20 de septiembre de 1923, p. 1.

45 "Evolución", en Nueva Iberia, 18 de septiembre de 1923, p. 1.

46 ¿En el principio del fin o el fin del principio?”, en La Voz de Soria, 18 de septiembre de 1923, p. 1; y La Voz de Soria, 14 de septiembre de 1923, p. 3 .

47 "Movimiento trascendental", en El Diario palentino, 17 de septiembre de 1923, p. 1.

48 "Llegó la crisis", en La Provincia, 14 de septiembre de 1923. p. 1.

${ }^{49}$ El Progreso, 18 de septiembre de 1923, p. 1.

${ }^{50}$ El Orzán, 14 de septiembre de 1923, p. 1; 15 de septiembre de 1923, p. 1.

51 "Los militares y el país", en El Eco de Santiago, 17 de septiembre de 1923, p. 1.
} 
caciquismo era la principal causa. Ante la inactividad de los liberales, agradeció que hayan sido los militares quienes ejercieran el cambio, debido al miedo de caer en el "soviet" y la revolución $n^{52}$.

El respeto a la Constitución y el apoyo del pueblo fueron las bases por la cuales, para el Heraldo Alavés, debían contar los golpistas. Exigieron contundencia dentro del respeto constitucional; de no ser así, también advierten que el país caería en la revolución social ${ }^{53}$. Otros como El Eco de la Comarca de Amposta apoyaron el golpe de Estado y el establecimiento de la Dictadura justificando al Ejército como garante de la paz y el orden ${ }^{54}$; y La Palanca de Guadalajara sindicó la Constitución como un ente infectado por el caciquismo, e invocó a ese "cirujano de hierro" que hemos visto solicitado en líneas anteriores ${ }^{55}$.

\subsubsection{Opiniones cruzadas entre la prensa}

Otro de los aspectos que comúnmente aparecen en estos diarios a través de los editoriales o de secciones elaboradas expresamente para ello, es aquel se refiere al análisis de las opiniones de otras publicaciones. Muchos se limitaron a recoger las palabras de los periódicos más importantes como El Sol, La Libertad, La Opinión, El Liberal, el Universo o ABC, pero otros se dedicaron a lanzar acusaciones directas, más aún si la ideología del periódico no era similar a la propia. El Imparcial criticó el cambio de posición de muchos de estos diarios, al ponerse todos de acuerdo en declarar como culpables a los políticos liberales. Las acusaciones en este sentido son abundantes, por lo que desde el diario madrileño realizaron un llamamiento para que los partidos se defendieran de las incriminaciones que sobre ellos recaían ${ }^{56}$. El diario murciano El Tiempo denunció a aquellos periódicos que se habían puesto del lado de los golpistas, explicando que, si la prensa en general se había decantado por el movimiento militar, fue por el sentimiento generalizado de cansancio. Este diario analizó bastantes publicaciones, enumerando aquellas que se habían mostrado en desacuerdo con el movimiento militar: El Imparcial, El Liberal, La Libertad y El Socialista. La crítica más dura fue para la prensa de izquierdas, al tacharla de falsa debido a su ambigüedad ante el movimiento. A los diarios antimilitaristas también los culpó de haber virado hacia la conveniencia del golpe y, respecto del diario católico El Debate, lo acusó directamente de estar de acuerdo con la censura ${ }^{57}$.

También es común que se reproduzcan las manifestaciones de las organizaciones de izquierdas en otros diarios, dado el temor a una huelga general o una respuesta violenta. Así,

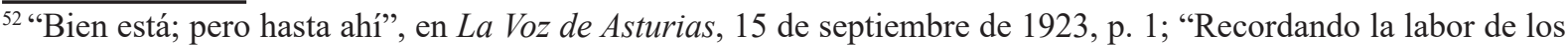
concentrados", en La Voz de Asturias, 18 de septiembre de 1923, p. 1; "Comentarios" en La Voz de Asturias, 19 de septiembre de 1923, p. 1; y "Hacia una solución patriótica", en La Voz de Asturias, 20 de septiembre de 1923, p. 1. ${ }^{53}$ Peñaflor, Miguel, "El deber de ahora”, en El Heraldo Alavés, 18 de septiembre de 1923, p. 1.

54 “Cambio de Régimen", en El Eco de la comarca, 16 de septiembre de 1923, p. 1.

55 "Hacia una nueva España", en La Palanca, 19 de septiembre de 1923, p. 1.

${ }^{56}$ El Imparcial, 15 de septiembre de 1923, p. 1; y 18 de septiembre de 1923, p. 1.

${ }^{57}$ El Tiempo, 16 de septiembre de 1923, p. 1; 18 de septiembre de 1923, p. 1; 19 de septiembre de 1923, p. 1; 20 de septiembre de 1923, p. 1; y 21 de septiembre de 1923, p. 1.
} 
El Heraldo de Madrid, recogió las manifestaciones del PSOE, la Casa del Pueblo, comunistas, anarquistas y sindicalistas ${ }^{58}$. Los diarios El Sol y La Voz también transcribieron los comunicados de las formaciones de izquierdas, además de recoger el manifiesto de la Federación Patronal, que apoyaba el golpe de Estado ${ }^{59}$.

\section{$\underline{1.1 .5 \text { La censura en la prensa }}$}

Fue un tema muy tratado junto con el de las garantías constitucionales. Para El Imparcial la censura no suponía la mejor solución puesto que la opinión pública era el punto donde, según ellos, debían apoyarse los golpistas ${ }^{60}$. Una “caída en los mismos errores de siempre" es la descripción que dio el Heraldo de Madrid a la suspensión de las garantías constitucionales ${ }^{61}$. Por su parte, El Sol y La Voz recogieron las declaraciones realizadas por El Debate, las cuales pedían el establecimiento de una ley de prensa más rígida ${ }^{62}$. El juicio más duro fue lanzado desde las líneas de La Opinión, que presentó el menoscabo que sufría la opinión popular y la libertad de información, pilar fundamental de la sociedad, atacando directamente al Directorio Militar por ser complaciente con la prensa que le fue afín. Quizá sea esta la razón por la que el día 18 su editorial apareció censurado, debido a que en él se criticaba a Primo de Rivera respecto del modo de ejercer las reformas ${ }^{63}$.

La Correspondencia de España, de signo conservador, se hizo eco desde Madrid de la suspensión de varios diarios de Cataluña: El Diluvio, El Progreso y Solidaridad Obrera, y se quejó por el control de las comunicaciones ${ }^{64}$. Crónica Meridional y La voz de Asturias protestaron por el mismo motivo ${ }^{65}$. Para otros diarios, la excepción de la situación definía a la censura como un acto temporal y esencial, reflejado en el diario El Tiempo ${ }^{66}$. Por el contrario, el periódico La Provincia de Lugo expuso su malestar al denunciar la censura por la que pasaban, no solo ellos, sino todos los diarios de su territorio, evidenciando la supuesta libertad de información que tenían los diarios de la capital ${ }^{67}$.

\subsubsection{Opiniones personales}

Las opiniones de personajes públicos aparecieron en La Voz de Asturias, donde se expusieron las impresiones del exministro de Fomento, Ossorio y Gallardo, respecto del golpe de Estado,

\footnotetext{
${ }_{58}$ El Heraldo de Madrid, 13 de setiembre de 1923, p. 2; y 14 de setiembre de 1923, p. 2.

${ }^{59}$ El Sol, 14 de septiembre de 1923, p. 2; y La Voz, 14 de septiembre de 1923, p. 2.

${ }^{60}$ El Imparcial, 15 de septiembre de 1923, p. 1.

${ }^{61}$ Heraldo de Madrid, 14 de septiembre de 1923, p. 1.

${ }^{62}$ El Sol, 18 de septiembre de 1923, p. 1; y La Voz, 18 de septiembre de 1923, p. 1.

${ }^{63}$ “Censura y Libertad”, en La Opinión, 16 de septiembre de 1923, p. 1; y La Opinión, 18 de septiembre de 1923, p. 1.

${ }_{64}^{64}$ La Correspondencia de España, 14 de septiembre de 1923, p. 1.

${ }^{65}$ Crónica Meridional, 14 de septiembre de 1923, p. 1; y La voz de Asturias, 15 de septiembre, p. 1.

${ }^{66}$ El Tiempo, 19 de septiembre de 1923,p. 1.

${ }_{67}$ "Dios ponga tiento en las manos de todos", en La Provincia, 15 de septiembre de 1923, p. 1.
} 
el cual denunciaba la actuación fuera del constitucionalismo. El Liberal publicó un artículo de Ramiro de Maeztu donde se acusaba abiertamente a los políticos liberales por su inoperancia y patrimonialización de las administraciones públicas ${ }^{68}$. El diario murciano El Tiempo denunció directamente al diario La Libertad, órgano de expresión del ministro de Gobernación Santiago Alba, tras las declaraciones realizadas por este a favor de la democracia y la libertad ${ }^{69}$. Por otra parte, varios son los diarios que recogen las palabras del escritor y filósofo tradicionalista Juan Vázquez de Mella respecto de la definición de "dictadura", estableciendo paralelismos entre lo que ocurría y dicha forma de gobierno; tal fue el caso de El Heraldo Alavés ${ }^{70}$. La figura de Mussolini se utilizó también para describir las semejanzas que el movimiento presentaba con el régimen fascista italiano; así lo hizo Crónica Meridional que demandaba para España una figura como la del dirigente italiano ${ }^{71}$.

\subsubsection{La Acción}

Hemos dejado para este último apartado el análisis del monárquico La Acción, tras su viraje radical al conservadurismo. Intentó convertirse en el órgano de expresión de la dictadura y simpatizó con el fascismo italiano. Sus editoriales y artículos que analizan el golpe de Estado son quizá lo más nutrido de la prensa española sobre el acontecimiento. El mismo día 13 definió el golpe de Estado como "adecentamiento", atacó directamente a todos los políticos profesionales y manifestó que venía denunciando la situación desde hacía tiempo. Su posicionamiento quedó claro con un artículo titulado "Nosotros con el ejército": un alegato en favor de la actuación castrense. Cargó contra el diario La Libertad por tildar al movimiento de "impunista". Se hizo eco de cómo el pueblo había apoyado el levantamiento sin sobresaltos. Recogió la opinión de otros diarios como El Liberal, El Sol, ABC o El Imparcial, o de organizaciones como la Confederación Patronal Española, y prestó gran atención a las manifestaciones de la izquierda, sobre las que alertó acerca de una supuesta convocatoria de huelga general. También se centraron en la búsqueda de responsabilidades entre los políticos profesionales. Las continuas querellas que Santiago Alba tenía contra el director de este diario por difamaciones, Delgado Barreto, se convirtieron en uno de los temas más tratados, siendo motivo de satisfacción el proceso abierto contra el Ministro de Gobernación, ya en el exilio. Este tema se utilizó para acusar abiertamente a los políticos del régimen caído, asimilando el proceso contra Alba como una búsqueda de responsabilidades colectiva. Reclamó un régimen de severidad contra el caciquismo y el atropello que sufría la Constitución, demandando una reforma de la administración. Tras las manifestaciones de los grupos de izquierda, equiparó a los políticos socialistas con los liberales,

\footnotetext{
${ }^{68}$ El Globo, 20 de septiembre de 1923, p. 2; y La Voz de Asturias, 20 de septiembre de 1923, p. 1.

69 "Temas políticos", en El Tiempo, 12 de septiembre de 1923, p. 1.

70 "El deber de ahora", en El Heraldo Alavés, 18 de septiembre de 1923, p. 1.

71 "La Solución", en Crónica Meridional, 16 de septiembre de 1923, p. 1.
} 
al manifestar que el movimiento obrero había divido a los trabajadores. El diario La Acción dejaría de publicar al año siguiente para pasar su director, Delgado Barreto, a dirigir La Nación, órgano oficial de expresión de la dictadura ${ }^{72}$.

\subsection{Prensa obrera y sindicalista}

El temor a una convocatoria de huelga general o a actos violentos hizo que muchos de los diarios prestaran atención a las manifestaciones del PSOE, UGT y la Casa del Pueblo de Madrid. La postura general de la izquierda quedó reflejada en el diario El Socialista, demandando serenidad y calma. Analizaron el golpe desde la óptica del desánimo que se había ido acumulando en los ciudadanos desde hace años. Para ellos, la sublevación fue una reacción contra el Informe Picasso, el cual buscaba las responsabilidades tras el desastre del Annual, en consonancia con el “impunismo" que manifestaba La Libertad. Las directivas del PSOE y UGT expusieron que no sentían apego por las élites políticas, igual que culparon a los dirigentes castrenses de levantarse contra aquellos que los habían elevado a su posición. Habrían deseado que fuera el pueblo y no el Ejército el que iniciara el movimiento de cambio, por lo que estableció la fecha de 1917 como dislocamiento de la sociedad española. Aunque no apoyaban a los partidos liberales, se preguntaron por las causas que los habían llevado a no defenderse del golpe de Estado. Este último era visto como un mero estado de transición para el establecimiento de un nuevo grupo político en el gobierno, al puro estilo de un pronunciamiento. El beneplácito con que la sociedad acogió los hechos les causó sorpresa y acusaron abiertamente a las derechas del apoyo dado al mismo. La huelga general o la insurrección que muchos de los periódicos temieron fue una mera advertencia realizada desde las páginas de El Socialista, realizable solo si las reformas prometidas por los militares no se llevaban a cabo. Una vez instalada la censura de prensa, sus quejas van esta dirección, ya que no se les permitió publicar nada sobre la guerra de Marruecos o criticar la situación. La censura actuó con contundencia, pues es posible observar grandes espacios en blanco en sus columnas. El día 17 presentaron un editorial en que se defendían de las acusaciones de no haber sabido contrarrestar el movimiento militar, y declaró que no era el momento de realizar revoluciones proletarias ni de las llamadas a la acción que personalidades de partidos liberales hicieron. No obstante, se hicieron eco de las peticiones de comunistas y anarquistas para establecer un frente común. Su "no" fue rotundo ante los ataques que los socialistas habían sufrido anteriormente por la izquierda más radical ${ }^{73}$.

\footnotetext{
72 "Prescripciones higiénicas", en La Acción, 14 de septiembre de 1923, p. 1; "La desaparición del señor Alba", en La Acción, 15 de septiembre de 1913, p. 1; "Vamos a ver si es verdad" y "Recuerdos del antiguo sistema", en $L a$ Acción, 17 de septiembre de 1923, p. 1.

73 "¡Serenidad, trabajadores!” y "Significación del movimiento”, en El Socialista, 13 de septiembre de 1923, p. 1; "En estas horas tristes", en El Socialista, 14 de septiembre de 1923, p. 1; "Bajo el directorio militar", en El Socialista, 15 de septiembre de 1923, p. 1; "Estamos en nuestro puesto", en El Socialista, 17 de septiembre de 1923, p. 1; El Socialista, 18 de septiembre de 1923, p. 1; y El Socialista, 19 de septiembre de 1923, p. 1.
} 
Respecto de la CNT, su ilegalización mermó su actividad considerablemente. Nuestro análisis del Solidaridad Obrera solo ha dado pequeños resultados. El tema principal que trataron versó sobre la declaración de la ley marcial, que se proyectó sobre las reuniones de los sindicatos, su suspensión y las detenciones de simpatizantes. Realizaron un pequeño estudio de la caída del anterior gobierno, donde destacaron la falta de apoyos del mismo y denominando a los políticos liberales como "los caídos". Para esta publicación, los caciques debían ser los que tenían que haber apoyado a los partidos liberales cuando ocurrió el golpe de Estado ${ }^{74}$.

\subsection{Prensa republicana}

Las causas principales que esgrimieron los diarios republicanos respecto del golpe de Estado remiten al desastre del Annual como motivo principal. El Luchador alicantino analizó el manifiesto de Primo de Rivera respecto de la desaparición del caciquismo y presentó la guerra de Marruecos como un despilfarro absoluto de recursos ${ }^{75}$. De igual manera, el diario fundado por Blasco Ibáñez, El Pueblo de Valencia, presentó días antes del golpe un análisis del desastre de Marruecos y sus responsabilidades ${ }^{76}$. Y con un poco de retraso, El Progreso de Tenerife analizó el gasto que generaba la guerra como la principal causa de la situación el país ${ }^{77}$.

El propio golpe de Estado es aprovechado por este tipo de diarios para reivindicar sus ideales. El Pueblo, más mesurado, marcó como fecha de inicio el desastre del 98, momento que culminó en el actual levantamiento militar. Reflexionó sobre el separatismo reclamando más autonomía regional para acabar con esta tendencia. Para ellos, este movimiento revolucionario debería traer la República. Destaca su interpretación de los escritos de Costa en un sentido republicano, en el sentido de demandar también la figura del "cirujano de hierro". Acusaron directamente a Maura y su "revolución desde arriba" como causa del levantamiento que acababa de ocurrir ${ }^{78}$. Del mismo modo, El Luchador utilizó los textos de Costa como justificación del proceso regenerativo, pero desde los preceptos democráticos y el parlamentarismo. Para ellos, los partidos liberales y el caciquismo eran los verdaderos culpables de la situación. Su alegato al republicanismo surge también del análisis de los pronunciamientos del siglo xIX y el caduco régimen de la Restauración, del cual deducen que la revolución la debía realizar el pueblo. Aun así, confiaron en una salida constitucionalista y en la convocatoria de nuevas elecciones ${ }^{79}$.

Diferente republicanismo se manifestó por medio de los tinerfeños El Progreso y La Prensa. El primero manifestó sus simpatías hacia el golpe de Estado por cargar con el proceso regenerador del país, comparándolo también con los pronunciamientos del siglo XIX, pero

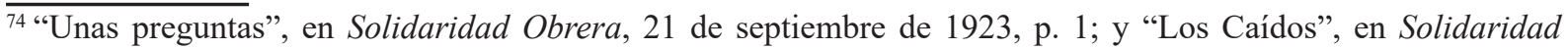
Obrera, 22 de septiembre de 1923, p. 1.

${ }^{75}$ El Luchador, 14 de septiembre de 1923, p. 1.

76 "Mosaico", en El Pueblo, 13 de septiembre de 1923, p. 1.

77 "Dos palabras", en El Progreso, 13 de septiembre de 1923, p. 2.

78 "Coincidencias", en El Pueblo, 15 de septiembre de 1923, p. 1.

${ }^{79}$ El Luchador, 14 de septiembre de 1923, p. 1; 15 de septiembre de 1923, p. 1; y 18 de septiembre de 1923 , p. 1.
} 
aplaudiendo la ausencia de un derramamiento de sangre. Su conveniencia con el golpe de Estado vino de las esperanzas puestas en que el movimiento tuviera la profundidad necesaria para que llegara la República ${ }^{80}$. El segundo diario manifestó su sorpresa ante el pacifismo de los hechos y la facilidad con que había triunfado, aunque se preguntaron por la vulneración de la Constitución y valoraron un posible enfrentamiento entre el poder civil y el militar ${ }^{81}$. Destacamos, para concluir, las manifestaciones de La Voz de Menorca, periódico afín a Lerroux, que advirtió a los militares que estaban actuando desde la posición establecida gracias a los mismos partidos liberales y que el problema, en general, provenía del régimen de la Restauración ${ }^{82}$.

\subsection{Prensa nacionalista}

Sobre este aspecto hemos realizado un análisis de tres publicaciones representativas que nos permitieran acercarnos a su posición. Así, La Veu de Catalunya, diario ligado a la Lliga Catalana, no se sorprendió ante las circunstancias que llevaron al movimiento militar. Tildaron de "inconscientes" a los gobiernos liberales de Madrid por desoír las reivindicaciones de Cataluña y, en concreto, la política llevada por Santiago Alba. Manifestaron también sus temores ante la represión contra el separatismo, pero esperaban de los nuevos gobernantes una España que reconociera sus pueblos y se olvidara el uniformismo y el centralismo imperante ${ }^{83}$.

El órgano de prensa del PNV, Euzkadi, se limitó el 14 de septiembre a describir los acontecimientos del golpe de Estado y reproducir el manifiesto del marqués de Estella en primera plana. No realizó ningún editorial en que opinara sobre la situación en los días posteriores al golpe, aunque sí respecto de la censura en la prensa ${ }^{84}$. En Galicia, la publicación quincenal gallega $A$ Nosa Terra. Idearium das hirmandades, no se encuentra digitalizada para las fechas que estamos tratando, aunque exponemos aquí el número del mes de julio de 1924, que trata sobre el día de la región gallega y lo difícil que resulta una celebración de este tipo dentro de una dictadura impuesta ${ }^{85}$.

\subsection{Prensa tradicionalista y católica}

La preocupación de los diarios católicos y tradicionalistas vino expresada por la publicación de artículos referentes al nacionalismo y al separatismo catalán días antes del golpe de Estado. El tradicionalista El Siglo Futuro mostró la complacencia con que la sociedad se había tomado el movimiento, aprovechado la situación para realizar reivindicaciones de carácter

\footnotetext{
$\overline{80 \text { "La ausencia de }}$ opinión pública", en El Progreso, 15 de septiembre de 1923, p. 1; y "La disolución de las Cortes", en El Progreso, 18 de septiembre de 1923, p. 1.

81 "Momentos críticos", en La Prensa, 16 de septiembre de 1923, p. 1.

${ }^{82}$ La Voz de Menorca, 19 de septiembre de 1923, p. 1.

83 "Serenitat i expectatio", en La Veu de Catalunya, 14 de septiembre de 1923, p. 6.

${ }^{84}$ "El censor, mi pluma y yo", en Euzkadi, 22 de septiembre de 1921, p. 1.

85 "A Actualidade Galega", en A Nosa Terra, 25 de julio de 1924, p. 3.
} 
tradicionalista: "el momento es idóneo para establecer unas Cortes corporativas"; y presentó al liberalismo como inoperante, proponiendo como ejemplo, para ello, los pronunciamientos militares del siglo XIX. No perdieron tampoco la oportunidad para criticar al resto de la prensa nacional, al acusarla de apoyar el movimiento militar cuando antes lo hicieron al anarquismo y al socialismo, en una referencia explícita a El Sol; y atacó directamente a La Libertad como defensor del liberalismo. Para concluir, agasajó a la prensa católica que apoyaba unánimemente al golpe militar ${ }^{86}$.

Dicha prensa católica tuvo como estandarte a El Debate, modelo a imitar por muchas de las publicaciones periódicas católicas en el ámbito nacional. Este diario se puso de parte de los militares de forma inmediata como símbolo del verdadero sentimiento nacional, "paladines de justicia" y "guardianes de la moral". Enumeró los antecedentes del golpe de Estado, acusando directamente a la política liberal y justificó el movimiento como robustecimiento de la Monarquía. Declaró expresamente que colaborarían con la causa, pero el gobierno militar debía ser transitorio, dictatorial y con un objetivo de saneamiento de la administración. Destacó la petición de regeneración moral a través de la eliminación del alcoholismo, la pornografía, la propaganda sindicalista y la separatista. No obstante, sus esperanzas siempre estuvieron puestas en el establecimiento de un nuevo gobierno. Respecto de la censura, la consideraron como necesaria, puesto que para ellos la prensa nacional con libertad de expresión influía negativamente sobre la opinión pública, sobre todo en lo que respecta al tema de Marruecos y la conflictividad social. También se hizo eco de las manifestaciones de la prensa de izquierdas, lo que para ellos fue suficiente justificación para llevar a cabo el golpe de Estado ${ }^{87}$.

Otras manifestaciones, como la del soriano El Avisador Numantino, presentaban el movimiento como "redentor" y a Primo de Rivera como "salvador". Su editorial es un ataque al caciquismo y a los órganos de expresión de los partidos liberales, causantes de la degeneración del país. Sobre las manifestaciones de los políticos liberales sintieron auténtico desprecio. Su concepto del país es de ingobernabilidad, por lo que se mantuvieron a la expectativa de las publicaciones de los decretos que los militares llevarían a cabo y aplaudieron con efusividad aquel que reformaba el funcionariado público ${ }^{88}$. El separatismo y los nacionalismos periféricos son crudamente denominados como "víboras" por El Defensor de Córdoba. Este diario también mostró un análisis de la dictadura a través de las palabras de Vázquez de Mella, exponiendo como ejemplo sus textos y presentando el golpe como una acción ordenadora de la patria, y no

\footnotetext{
86 "Escrúpulos y escándalos”, en El Siglo Futuro, 17 de septiembre de 1923; y "La prensa ante la nueva situación”, en El Siglo Futuro, 17 de septiembre de 1923.

${ }^{87}$ El Debate, 13 de septiembre de 1923, p. 1.; "Un deber de patriotismo", en El Debate, 14 de septiembre de 1923, p. 1; "Un gobierno popular", en El Debate, 15 de septiembre de 1923, p. 1; y "La previa censura", en El Debate, 17 de septiembre de 1923, p. 1.

88 "Renovación patriótica", en El Avisador Numantino, 15 de septiembre de 1923, p. 1; "Sin cambiar de casaca" en El Avisador Numantino, 19 de septiembre de 1923, p. 1; y "Guardianes del orden”, en El Avisador Numantino, 22 de septiembre de 1923, p. 1.
} 
como despotismo y arbitrariedad ${ }^{89}$. Del mismo modo, el almeriense La Independencia se limitó a recoger la opinión de los periódicos católicos de tirada nacional y las palabras de Vázquez de Mella sobre la dictadura ${ }^{90}$.

Desde otro punto de vista, El Día de Palencia, órgano de expresión de la federación de sindicatos católicos-agrarios de dicha provincia, realizó un día antes del golpe de Estado un repaso al lamentable espectáculo de la política nacional. Mostró muchas de las características que nos hemos encontrado a lo largo de este estudio, como aquella que hace mención al "cirujano" de Joaquín Costa, el caciquismo y el recurso comparativo con Mussolini, pero de un modo vaticinador, puesto que su opinión fue expresada horas antes de que se diera el movimiento militar. Por ello, con la noticia del golpe de Estado, se posicionaron con los militares de forma expresa y también denominaron al movimiento como un "acto de redención”. Justificó el golpe presentando al propio gobierno como una amenaza para el orden y la patria. Es de destacar que también acudieron a la definición que hizo Vázquez de Mella respecto de la dictadura en tiempos de transición ${ }^{91}$.

\section{Conclusiones}

Se pone de relieve que, de una forma global y exceptuando a cierta prensa liberal afín al gobierno de concentración, el posicionamiento está claramente del lado de los golpistas. En muchas líneas hemos visto que se justifica el objetivo y no los medios, incluso es aplaudida la posición de Alfonso XIII al apoyar el movimiento. Esta consideración es achacada al cansancio de la sociedad con los partidos turnistas y el régimen de la Restauración [véase la fig. 1]. Pero existe un reparo que aparece reiteradamente: es el respeto al constitucionalismo y al parlamentarismo por parte de aquellos que, días antes, apoyaban el régimen liberal. De ahí que la mayor parte de los diarios desearan que el nuevo régimen establecido tuviera un carácter de transicionalidad y regeneración. En un principio, estas fueron las manifestaciones de Primo de Rivera y el Directorio Militar, pero pasado el tiempo, la creación de la Unión Patriótica como partido único, el Somatén Nacional como guardia cívica y el intento de institucionalización del régimen a través de un nuevo proyecto de constitución acabó con estos deseos.

\footnotetext{
$\overline{{ }^{89} \text { El Defensor de }}$ Córdoba, 14 de septiembre de 1923, p. 1; "Lenguas de víbora”, en El Defensor de Córdoba, 13 de septiembre de 1923, p. 1; "Concepto de la Dictadura", en El Defensor de Córdoba, 17 de septiembre 1923, p. 1; y "El deber de ahora", en El Defensor de Córdoba, 18 de septiembre de 1923, p. 1.

90 "Era irremediable" en La Independencia, 19 de septiembre de 1923, p. 1; y "El deber de ahora", en $L a$ Independencia, 20 de septiembre de 1923, p. 1.

${ }^{91}$ El Diario de Palencia, 15 de septiembre de 1923, p. 2; 17 de septiembre de 1923, p. 1; y 18 de septiembre de 1923, p. 1 .
} 
Figura 1: Número de argumentaciones que justifican el golpe de Estado expuestas en las publicaciones.

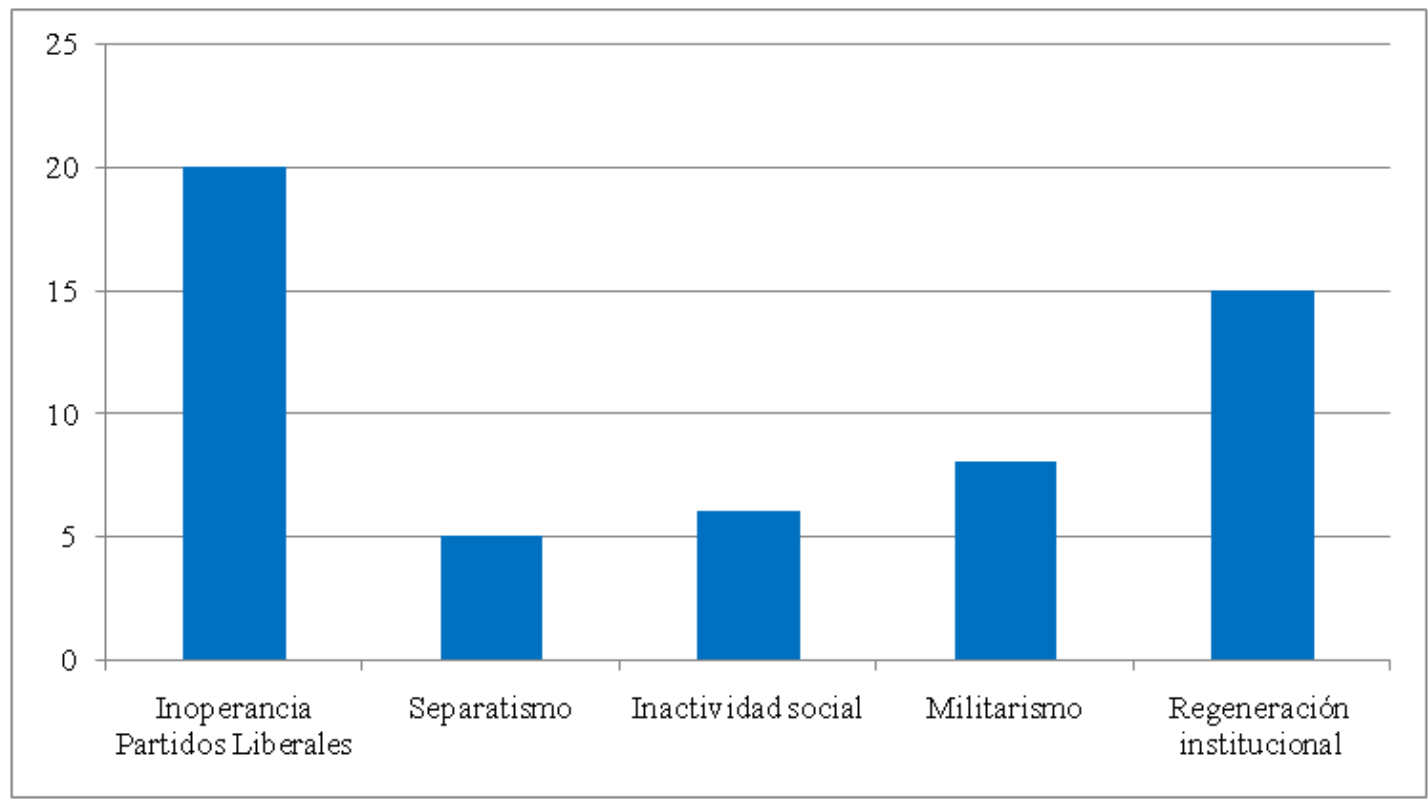

Fuente: Elaboración propia.

La corrupción, los partidos liberales y el caciquismo fueron considerados como los principales problemas por la opinión de casi todos los diarios, exceptuando los republicanos, que se centraron más en la guerra de Marruecos y responsabilizaron directamente a los partidos liberales. Dicha responsabilidad es reivindicada por parte de los editoriales, siendo el Ministro de Gobernación el principal acusado, tal y como se muestra en el pleito con Delgado Barreto de La Acción.

La prudencia y la expectación por ver cómo se desarrollaban los acontecimientos son manifestadas prácticamente por todos los diarios, destacando que la prensa de izquierdas recalcó en este sentido que las posibles manifestaciones o algaradas escaparían a su control y mando. Del modo contrario, la cercanía de la Revolución rusa de 1917 y la huelga general del mismo año causaron bastante temor en la prensa conservadora, tradicionalista y católica, que esperaban una huelga general y, si fracasaba el golpe, la revolución social y el establecimiento de un gobierno socialista. De este temor salieron las advertencias a los militares para que se apoyasen en las bases sociales y que no dieran la espalda al pueblo, ya que podía acarrear dichas consecuencias. Aun así, Primo de Rivera fue consciente y permitió la entrada de Largo Caballero como representante socialista en el Consejo de Trabajo y el establecimiento de los Comités Paritarios para la resolución de conflictos laborales.

Las acusaciones cruzadas entre la prensa de distintas ideologías fue la norma general. Los diarios católicos y tradicionalistas son relevantes en este aspecto por la dureza de sus declaraciones contra la prensa liberal y de izquierdas en general, a la que acusaba de conveniencia respecto 
del golpe de Estado. En realidad fue así, pero hay que exceptuar a diarios como El Imparcial, El Liberal, La Libertad y El Socialista. Es de destacar la alusión a Joaquín Costa y Juan Vázquez de Mella en muchos de los editoriales, lo que nos da una muestra del pensamiento político dominante de la época. Por lo que general, el regeneracionismo de Costa aparece en bastantes publicaciones, independientemente de su posición ideológica, aunque la prensa católica recaló más en las ideas de Vázquez de Mella.

Otra cuestión a tener en cuenta son las ausencias o el vacío informativo de determinados temas durante estos días en las líneas de opinión. Si existen acusaciones cruzadas entre opiniones de distintas ideologías entre periódicos del país, no se recoge apenas ninguna información de lo que la prensa internacional o corresponsales del exterior pudieron comentar sobre el golpe de Estado, lo que nos permite abrir una nueva línea de investigación para intentar realizar una nueva comparación entre las publicaciones periódicas nacionales y las internacionales. La única excepción al respecto es la del diario Euzkadi que recogió las impresiones de Le Petit Journal francés ${ }^{92}$.

Como consideración general y conclusión, prácticamente toda la prensa que hemos analizado esperaba que el golpe de Estado se convirtiera en un régimen de transicionalidad y regeneración. Pasado el tiempo, estas esperanzas se fueron diluyendo según el devenir de los acontecimientos realizados por el Directorio Militar y la pérdida del apoyo social, tantas veces reclamado en dichas publicaciones.

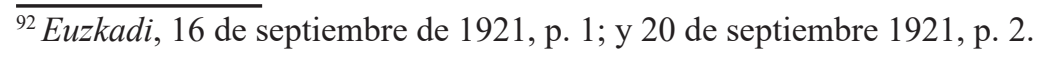

